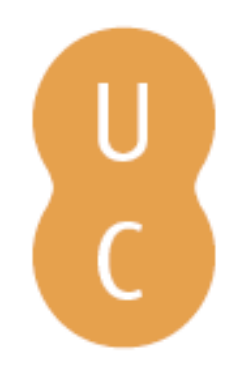

\title{
pompalina
}

\section{Para uma teoria metafísica da civilização africana}

Autor(es): $\quad$ Laranjeira, José Luís Pires

Publicado por: Imprensa da Universidade de Coimbra

URL

persistente: URI:http://hdl.handle.net/10316.2/43542

DOI: $\quad$ DOI:https://doi.org/10.14195/978-989-26-1343-7_43

Accessed : $\quad$ 26-Apr-2023 07:02:42

A navegação consulta e descarregamento dos títulos inseridos nas Bibliotecas Digitais UC Digitalis, UC Pombalina e UC Impactum, pressupõem a aceitação plena e sem reservas dos Termos e Condições de Uso destas Bibliotecas Digitais, disponíveis em https://digitalis.uc.pt/pt-pt/termos.

Conforme exposto nos referidos Termos e Condições de Uso, o descarregamento de títulos de acesso restrito requer uma licença válida de autorização devendo o utilizador aceder ao(s) documento(s) a partir de um endereço de IP da instituição detentora da supramencionada licença.

Ao utilizador é apenas permitido o descarregamento para uso pessoal, pelo que o emprego do(s) título(s) descarregado(s) para outro fim, designadamente comercial, carece de autorização do respetivo autor ou editor da obra.

Na medida em que todas as obras da UC Digitalis se encontram protegidas pelo Código do Direito de Autor e Direitos Conexos e demais legislação aplicável, toda a cópia, parcial ou total, deste documento, nos casos em que é legalmente admitida, deverá conter ou fazer-se acompanhar por este aviso.

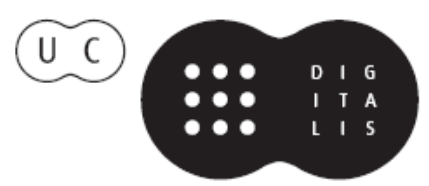




\section{FERNANDA CRAVIDÃO}

\section{IÚCIO CUNHA}

PAULA SANTANA

\section{NORBERTOSANTOS}

(ORG.)

\section{ESPAÇOS E TEMPOS EM GEOGRAFIA}

HOMENAGEM A ANTÓNIO GAMA

IMPRENISA DÁ UNIVERSIDADE DE COIMBRA COIMBRA UNIVERSITY PRESS

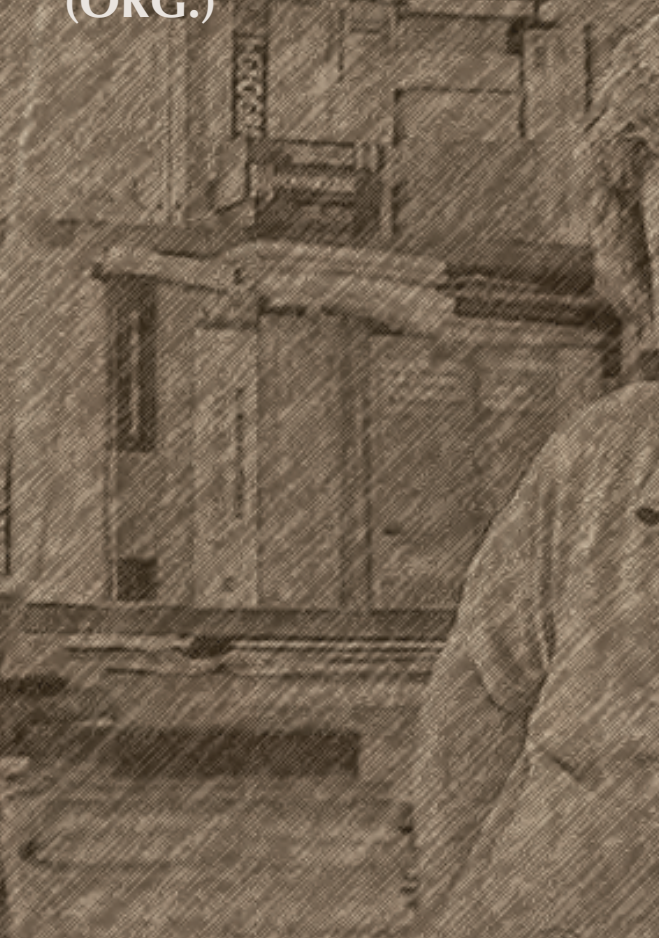




\section{PARA UMA TEORIA METAFÍSICA DA CIVILIZAÇÁO AFRICANA}

José Luís Pires Laranjeira/pires.laranjeira@gmail.com

Departamento de Línguas, Literaturas e Culturas da Faculdade de Letras da Universidade de Coimbra

\section{Definição}

Uma Civilização define-se como um conjunto e um processo de diversificadas culturas, enquanto modos de transformação da natureza e da sociedade, que se desenvolvem com base numa espacialidade ampla, abrangendo povos muito diferentes, durante um prolongado lapso temporal, e influenciando povos e lugares fora do espaço original. A África é o continente, o espaço onde nasceu e de desenvolve a Civilização Africana, cuja influência passou para as Américas, a Europa Ocidental e outras regiôes do Globo, através da expansão almorávida e do tráfico negreiro, entre outros fluxos de (e)migrantes, como os comerciais ou mesmo dos refugiados modernos. A Civilização Africana pode definir-se também como o triunfo milenar do engenho do Ser Humano para vencer as gigantescas dificuldades ambientais e transformar o imenso deserto de solidóes étnicas do Continente e da Diáspora no cadinho das solidariedades. Assim, em termos históricos e culturais, desde a chamada "Civilização Egípcia" (3000 a 900 a. C.) e o primeiro Estado Negro (pré)moderno, o do Gana (séculos IV-XIII), até ao poderoso movimento das Independências (anos 50-70 do século xx), passando pela intensa rede do Comércio Transahariano (séculos VII-XVI) e pelo Tráfego 
Negreiro para o Novo Mundo (Xvi-XIx), a Civilizaçấo Africana, com uma longa duraçáo lenta, alcança um arco de 5000 anos, se pensarmos nas multímodas criaçôes dadas ao mundo, desde a arquitetura faraónica (as célebres pirâmides do Egipto) ou do Mali (as conhecidas casas ou mesquitas bastante reproduzidas em fotos e estampas) à música de jazz e ao samba, voudou e candomblé. Mesmo que encurtemos esse arco temporal para o período que começa com o Reino do Gana, no século Iv, temos cerca de 1600 anos de uma Civilização em decurso. O contributo mais original da Civilizaçáo Africana para o Mundo assume-se em nove pilares estruturantes de um modo de ser e de fazer específico, que pode ser resumido pela expressão "o estar no mundo negro-africano e afro-asiático em situaçóes de excelência".

Esses nove pilares estruturantes da Civilização Africana, numa caracterização abrangente, generalizante, procuram dar conta de aspetos sobretudo espirituais das comunidades africanas, sejam elas do sul, do norte ou de qualquer outra latitude, aspetos esses, de algum modo, constantes, manifestaçóes que se revelam trans-históricas (o que implica, é um facto, uma visão com sua quota parte de metafísica) e que somente podem contribuir para a descrição do sistema civilizacional se tomadas no seu conjunto e em inter-relaçáo, sendo que qualquer delas, por si só, pode constituir também um atributo de outras civilizaçôes. Essa qualidade transepocal e de relação possibilita a compreensão estrutural e sistémica, mas igualmente dialética, da Civilização Africana como conjunto de manifestações de índole muito diversa, resultante de um longo e complexo processo de sociabilidade, apropriação instrumental da natureza e transformação do mundo. Para uma síntese, corre-se sempre o risco da essencialização (que pode tornar-se esquemática e mesmo estereotipada), mas, por outro lado, procura-se aqui, com intuitos inclusive didáticos, apresentar uma visão simplificada e totalizante das características que se associam eventualmente a qualquer espaço, época, sociedade ou cultura, tendo consciência de se tratar de uma tarefa problemática.

Os nove pilares estruturantes da Civilização Africana, enquanto núcleos conceptuais explicativos, ultrapassam qualquer condicionamento histórico e, por isso, podem ser considerados símbolos metafísicos, isto é, que funcionam, 
de acordo com a etimologia, para além da fisicalidade (implicando condiçôes específicas, materiais, de surgimento ou permanência) que determina a sua existência, mas, por outro lado, usufruem de sustentabilidade teórica porque podem ser verificados empiricamente, num dado momento, em mais do que uma cultura africana (por exemplo, a conceção de a palavra ser sagrada em várias cosmogonias, desde a dogon ou bambara à tshokwé) e, mais ainda, apresentam uma historicidade, um desenvolvimento que demonstra modificações temporais, porém vinculadas a condicionalismos específicos, materiais, históricos, sociais ou espirituais de certas regiôes, comunidades ou agenciamentos culturais. É por isso que o conceito de "família alargada" migrou das sociedades náo urbanas para as urbanas e transpôs mesmo o Atlântico, para se instalar nas Américas, com alteraçóes, passando a funcionar, entáo, como adjuvante de solidariedade em situaçôes de perigosidade política, social ou económica (veja-se o caso dos quilombos, no Brasil, ou dos fujóes de marronage, no Caribe, ambos fenómenos de resistência e fuga à escravidão e subsequente organização autónoma).

A Civilização Africana experimenta um ponto de chegada ou expressão grandiloquente na instância ideopolítica, durante o século xx, ao culminar na Consciência Panafricana, que procurou unir, idealística e também praticamente, todos os negros, do continente e da diáspora, em torno de programas injuntivos de pertença rácica e, precisamente, civilizacional, resgatando conceitos como o "orgulho de ser negro" e mostrando a possibilidade de emancipação, independência, igualdade e liberdade do negro, enquanto foco e agente de açóes afirmativas e autodeterminativas.

A Civilização Africana tem sido, de facto, usada pelos negros de todo o mundo como fundamento para atuaçôes políticas e sociais, esgrimindo argumentos sustentadores do sentido de pertença a uma matriz apresentada como demonstrativa de minimos denominadores comuns. Esses denominadores comuns incluem-se justamente nos nove pilares estruturantes da Civilizaçáo Africana. Assim, vejamos quais são eles. 


\section{Os nove pilares da civilização africana}

1) A ideia de ORIGEM, de que a África é o "berço da Humanidade", hipótese baseada nas descobertas arqueológicas e paleontológicas no Quénia, na Etiópia, etc., por cientistas como Leakey, ideia que tende a transformar-se no mito fundacionalista (fundacional), concede uma outra magnitude ao telurismo, já de si tão forte, da africanidade. O sentido de a África poder ser o berço dos Humanos atribui uma força e um orgulho suplementares aos africanos e afro-descendentes que têm consciência dessas hipóteses científicas. Essa ideia de Origem do mundo humano na África conecta-se com a de Mãe-África, do continente visto como um enorme regaço materno.

2) Associado à origem do homem e do "mundo" (ou mesmo do universo), surge a PALAVRA (= Nommo), como entidade fundadora e geradora de vida e de concretude. Comprovadamente, algumas etnias africanas têm na Palavra a revelaçáo do sagrado, na forma do poder gerador da vida, tal como acontece, por exemplo, na Bíblia, quando, no Génesis, aparece a ideia de que "o Verbo se fez carne”. Vejam-se Marcel Griaule, Dieterlen, Tempels, Kagame, entre outros, para a centralidade da Palavra em cosmogonias étnicas. A Palavra é comparada ao sémen (dizem os sábios de uma etnia não africana que o mundo, ideia essa inesperada, foi criado com uma masturbação), ao sopro, à seiva, à linfa, à saliva ou ao sangue (os fluidos vitais dos corpos animais, humanos e vegetais), podendo surgir como criaçáo da mulher, por via da menstruaçáo, ou como manifestaçáo espiritual, por intermédio da expiração. Em África, a Palavra, mais do que a linguagem, mediaçáo de pensamento e comunicação, é epifania genesíaca, autêntico processo de hominizaçáo e criação, é o logos (e locus) engendrador da substância do mundo, sem a qual (palavra) ele não existiria. Num Continente em que as etnias e as línguas existem aos milhares, nesse contexto de multiculturalismo e babelismo cosmopolita (há pessoas do meio não urbano que falam mais do que duas, ou mesmo cinco ou seis, línguas), é natural que a Palavra se apresente, na sua associaçáo com a vocalidade e a expressividade corporal, como a deusa dos deuses (os deuses são, na verdade, entidades anímicas), isto é, o deus máximo dos espíritos, como a deidade de todas as divinizaçôes, de todas as religaçôes. 
3) O FOGO associa-se ao Sol, estrela da luz intensa, geradora do calor sentido de maneira mais envolvente nos trópicos e no Equador: recorde-se que a África é o único continente cuja superfície é sensivelmente distribuída, de modo aproximado, para setentriáo e meridião. Concomitantemente, o Fogo, na sua forma quotidiana produzida pelo ser humano, nas queimadas de vegetação dos terrenos ou, então, por exemplo, nas forjas mais ou menos complexas, ganha um sentido mágico, ligação elemental às fórmulas primordiais do mundo (fogo, terra, ar, água) e ainda, enquanto elemento manipulado, forma de domínio da natureza e de poder na sociedade (forjar armas e utensílios de lavoura), sendo os seus manipuladores (o ferreiro, o "guardiāo") figuras com estatuto social considerável nas "comunidades construídas” (localidades, associações, regióes) ou nas "comunidades imaginadas/tradicionais" (seitas, grupos, clãs). O Fogo, associado ao calor e à luz, significa e simboliza o entusiasmo com que os africanos defrontam as agruras da vida, num Continente naturalmente hostil e cuja sociabilidade é complexa e difícil, pela diversidade de culturas e interesses pelas matérias-primas e outros produtos fulcrais, quer nas economias de trocas regionais, quer na economia-mundo (ouro, marfim, escravos, cola, madeira, malagueta, petróleo, etc.). É como se o Fogo, o calor, propiciasse, na envolvência ambiental (qual quentura amniótica, uterina), uma espécie de acalanto telúrico-materno, prolongamento complementar, na sua expressão qualitativa, da faceta telúrica do fundacionalismo, ideação mítica de África como Mãe-África, materna matriz do mundo e do universo.

4) O RITMO, ligado ao movimento, implica sempre o som presencial e indicia vivacidade e vitalismo. Pode-se observar, quer em África, quer noutro ponto do planeta, que, se náo tiver sido educado num ambiente digamos que aparentado ao rigorismo dos calvinistas ou de outras façóes da sociedade consideradas de costumes rígidos, o negro é mais solto e balanceado no seu andar e no comportamento - como se o comandasse uma rítmica interna mais forte do que a de outros continentes -, mais liberto da tristeza, do pessimismo e do derrotismo, quando considerado em situaçóes quotidianas que não impliquem guerra, fome, calamidade natural, migração forçada e outras causas trágicas de compreensível estado de desânimo. Mesmo nesses 
contextos, o africano tem reagido, bastantes vezes (genocídio ruandês, fome no Darfour, guerra civil do Biafra, etc.), de modo mais otimista graças ao seu vitalismo, de que o ritmo (isto é, o movimento sincopado vivido interiormente) é uma componente articulatória e expressiva, tanto no aspeto emocional quanto motor.

5) O HOMEM, ou $n t u$, segundo a raiz banta desta mesma palavra (bantu), e de acordo com o pilar conceptual da Origem, é, por definição, africano, o que significa que os bantos se consideram "os homens". A etnologia deu conta da pluralidade do homem africano, numa perspetiva de descentração relativista, como se lhe pode chamar. A conceção do homem, em muitas cosmogonias étnicas africanas, perfilando um Humanismo que somente atribui aos espíritos um valor semelhante, compara-se ao Humanismo renascentista europeu ou ao Humanismo chinês protagonizado pela filosofia e pela pedagogia de Confúcio. À semelhança de outros povos tão diversos, de outros continentes, os africanos, desde os Nuer (no Sudão) aos masai (no Quênia), observados regionalmente, consideram-se superiores aos seus vizinhos. Assim, não é nesta perspetiva local que o Humanismo surge como um atributo de regozijo, mas tomando o Continente na sua totalidade e comparando-o com outros povos de qualquer época: aí se vê como o africano (e o negro) se sente "O Homem".

6) Ora o Homem africano está intimamente relacionado com o sexto pilar, o COLECTIVO, porque, sendo ele também obviamente um indivíduo, somente se compreende o seu comportamento quando inserido na sociedade. Aí ele participa na teia de relaçóes que são de verdadeira solidariedade, onde a fraternidade e o conceito de "família alargada" explicam atividades e açóes em meios pequenos ou náo urbanos (ainda se manifestando nestes lugares). Subentende-se, pois, uma ideia de organização clânica a partir dos conjuntos de famílias alargadas. Pode-se sempre argumentar, por exemplo, que o sentido de grupo, de rede de auxílio e solidariedade, não funciona em certas circunstâncias (os negros brasileiros que ascendem socialmente são vítimas, tantas vezes, do isolamento, até pela sua diminuta representatividade), valendo-se cada qual dos seus meios privados, como em qualquer sociedade pós-moderna. Porém, são infindáveis os exemplos da cooperação "familiar", entre "primos" afastados 
e seus segmentos - os filhos dos tios são “irmãos” -, quando algum indivíduo passa por dificuldades materiais ou outras. De facto, tem perdurado o espírito comunitário, que leva, por exemplo, em regióes não urbanas, à partilha do trabalho de lavoura, à pastorícia coletiva ou à edificação conjunta, sobretudo nas situaçôes carenciadas (como nos bairros urbanos periféricos).

7) A PRAGMÁTICA, ou pragmatismo, é uma chave-mestra para explicar a capacidade de sobrevivência, no sentido de realização muito prática e eficiente, segundo padróes próprios, que atentam na transitoriedade e mutabilidade do homem que se movimenta segundo as necessidades não satisfeitas de alimentação, saúde, trabalho e educação. No caso de África, a satisfação das necessidades básicas é constantemente deficitária e envolve demandas gigantescas para a real eficácia das instituições sociais. A pragmática, em África, nada tem a ver com uma prática como que funcional. Pode-se apelar à sintomatologia do senso comum para a compreender como a melhor maneira, rápida e eficaz, de conseguir realizar os intentos.

8) A ESPERANÇA no continente africano foi sempre uma constante, na medida em que as dificuldades de todo o tipo, sobrehumanas, desde as geofísicas às da prepotência e usurpação por parte do colonialismo, moldaram mentalidades persistentes e perseverantes que apontam sempre para uma "potência futurante", que se tem baseado na juvenilidade do povo e na capacidade demográfica perante as calamidades e hecatombes da escravidão, das invasóes externas e das guerras intestinas. O princípio de esperança, de que falava Bloch, encontra uma justa medida no Homem africano e negro. Náo por acaso, o livro de poesia de Agostinho Neto, líder da libertação de Angola do colonialismo e seu primeiro presidente, intitula-se Sagrada Esperança, não exclusivamente messiânica ou prometeica, mas natural e cosmogónica, ontológica e social.

9) O NEGRO, na aceção de Homem $(n t u)$ e cor, que, no terreno da arte, cultura e ideologia, sustentou, e continua a sustentar, os fundamentos da civilização, é, por maioria, o representante do chamado "Continente Negro". Basta lembrar que, desde o negrismo ao movimento da Negritude (primeiro em França, na década de 30 do século xx, e, neste momento, no Brasil, para referir dois exemplos), a ideologização das açóes afirmativas do Negro elevaram 
a cor negra aos píncaros da positividade, da beleza e da grandeza, justificando a existência inequívoca de uma "estética negra". O Negro terá tendência a deixar de ser a cor simbólica da desgraça, do fatalismo, do horrível, do hediondo, da negatividade, para ser assumido com o significado de beleza, positividade, pureza, excelência e orgulho.

\section{Conclusão}

As conquistas e as liçôes da Civilização Africana constituem um património material e espiritual de Pan-africanidade, concitando a "reuniâo" de todos os negros com o objetivo de contribuir, no mundo, para a equidade e hominização de todos os humanos. Para alcançar tal objetivo, os africanos e os negros de todo o mundo terão, também eles próprios, de ultrapassar o estádio de desigualdade e desumanização que, entre si, igualmente sustentam.

\section{Bibliografia}

AA.VV. (1986). L'affirmation de l'identité culturelle et la formation de la conscience nationale dans l'Afrique contemporaine. reimp., Paris: UNESCO.

AA.VV. (1990). La pensée métisse. Croyances africaines et rationalité occidentale en questions. Paris/ Genebra: PUF/Cahiers de L'IUED.

AA.VV. (2000). Afrocentrismes. L'histoire des africains entre Égypte et Amérique, Paris, Karthala. Ahmad, Aijaz (2002). Linhagens do presente. São Paulo: Boitempo.

Altuna, P. Raul Ruiz de Asúa (1985). Cultura tradicional banto. Luanda: Secretariado Arquidiocesano de Pastoral.

Appiah, Kwame Anthony (1992). In my father's house. Nova Iorque/Oxford: Universidade de Oxford, (há tradução brasileira).

Bâ, Amadou Hampâté (2003). Amkoullel, o menino fula. São Paulo: Casa das Áfricas/Palas Athena.

Battestini, Simon (1997). Écriture et texte. Contribution africaine. Québec/Paris ; Universidade Laval/Présence Africaine.

Bhabha, Homi (1998). O local da cultura. Belo Horizonte: UFMG.

Bidima, Jean-Godefroy (1995). La philosophie négro-africaine. Paris, PUF.

Cissioko, Sékéné Mody (1996). Tombouctou et l'empire Songhay. Paris: L’Harmattan. 
Davidson, Basil (1981). À descoberta do passado de África. Lisboa: Sá da Costa.

Diop, Cheik Anta (1979). Nations nègres et culture. 2 vols. 3. ${ }^{\text {a }}$ ed., Paris: Présence Africaine.

Diop, Cheik Anta (1982). L'unité culturelle de l'Afrique Noire. 2.a ed., Paris: Présence Africaine.

Evans-Pritchard, E. E. (1978). Os Nuer. São Paulo: Perspectiva.

Ford, Clyde W. (1999). O herói com rosto africano. Mitos da África. São Paulo: Selo Negro.

Frobenius, Léo (1987). La civilisation africaine. Paris : Le Rocher.

Glissant, Édouard (1996). Introduction à une poétique du divers. Paris: Gallimard.

Glissant, Édouard (1997). Le discours antillais. Paris: Gallimard.

Goody, Jack (1987). A lógica da escrita e a organização da sociedade. Lisboa; Ed. 70.

Griaule, Marcel (2000) (1948). Dieu d'eau. Entretiens avec Ogotemmêli. Paris: Fayard.

Hernandez, Leila Leite (2005). A África na sala de aula. Visita à história contemporânea. São Paulo: Selo Negro.

Jacob, Ernst Gerhard (s.d.). Fundamentos da história de África. Lisboa: Aster.

Jahn, Janheinz (1963). Las culturas neoafricanas. México/Buenos Aires: Fondo de Cultura Económica.

Ki-Zerbo, Joseph (s.d.). História da África negra. ed. rev. e actualiz. 2 vols., Mem Martins: Europa-América.

Laranjeira, Pires (1995). A negritude africana de lingua portuguesa. Porto: Afrontamento.

Lewis, Ioan M. (1986). O islamismo ao sul do Saará. Lisboa: Universidade Católica Portuguesa.

Maquet, Jacques (1981). Les civilisations noires. Verviers : Marabout.

M'Bokolo, Elikia (2004). Afrique noire. Histoire et civilisations. Du XIX siècle à nos jours. 2. ${ }^{\text {a }}$ ed., Paris: Hatier/AUF.

Ndaw, Alassane (1997). La pensée africaine. Recherches sur les fondements de la pensée négro-africaine. Dakar: Les Nouvelles Éditions Africaines.

Paulme, Denise (1977). As civilizaçôes africanas. Lisboa: Europa-América.

Pourtier, Roland (2001). Afriques noires. Paris : Hachette.

Poutignat, Philippe \& Jocelyne Streiff-Fenart (1998). Teorias da etnicidade. São Paulo: UNESP.

Senghor, Léopold Sédar (1993). Liberté 5. Le dialogue des cultures. Paris: Seuil.

Smith, Stephen (2005). Atlas de l'Afrique, un continent jeune, révolté, marginalisé. Paris: Autrement.

Sow, Alpha I. et al. (1980). Introdução à cultura africana. Lisboa: Ed. 70.

Spivak, Gayatri Chakravorty (1999). A critique of postcolonial reason. Toward a history of the vanishing present. Cambridge/Londres: Universidade de Harvard.

Urrutia, Jorge (2001). Leitura do obscuro. Uma semiótica de África. Lisboa: Teorema.

Wauthier, Claude (1973). L'Afrique des africains. Inventaire de la Négritude. Paris: Seuil. 